\title{
Systematic review of situational prevention methods for crime against species
}

\author{
Dorothea Delpech* ${ }^{*}$, Herve Borrion and Shane Johnson
}

\begin{abstract}
Illegal activities concerning terrestrial species (TS) are responsible for a variety of health, environmental, economic and security issues. The majority of academic research associated with species relates to conservation, with few publications specifically investigating the scale of crimes impacting species or how they can be prevented. This article systematically reviews the available evidence about what works to prevent crime against terrestrial species. Of over 29,000 documents that were returned in the first stage of the review, these were filtered to just over 100. The remaining documents were partially or fully read to identify the most relevant documents to include in the final qualitative synthesis. The review results show there is a significant lack of primary research in this area, as only five articles were found that met the study inclusion criteria. The identified articles focus on the effects of two types of situational crime prevention interventions: community outreach and ranger patrol frequency. Community outreach was shown to have a significant impact on local poaching levels, while for patrolling the evidence suggests a positive impact on the discovery of poachers, animal carcasses and poaching paraphernalia, however, the quality of these studies varied greatly. To prevent the further decline of species numbers internationally, more effort should be invested in publicising existing research into the effectiveness of prevention strategies that have not reached the wider scientific audience, as well as the funding and promotion of research into alternate methods of crime prevention.
\end{abstract}

Keywords: Livestock, Wildlife, Crime, Poaching, Systematic Review, Patrols, Community Outreach

\section{Background}

The illicit exploitation of flora and fauna has a variety of negative impacts internationally including threats to health security (e.g. disease spreading, improper preparation of meat), national security (e.g. terrorism financing through illicit trade in species), environmental security (e.g. animal population decline and possible extinctions) and the economy (e.g. costs associated to the damage and removal of natural capital). In addition to the anthropocentric impacts described above, there is an increasing acknowledgement in the scientific literature and law of the direct impact of crimes on the species as sentient beings that can feel pain and suffering (Nurse 2016; Sollund 2016; Blattner 2019).

*Correspondence: dotdelpech@gmail.com

Department of Security \& Crime Science, University College London (UCL), 35 Tavistock Square, London WC1H 9EZ, UK
In 2014, the illicit trade in wild flora and fauna was estimated to be worth US\$7-23 billion internationally, in combination with other forms of environmental crime (Nellemann et al. 2014). However, the 'dark figure' of wildlife crime (i.e. unreported/undetected offenses), and difficulty in attributing a 'value' to natural capital, makes accurately estimating the total global costs of such crimes challenging. A recent publication by the World Bank aimed to account for the financial and economic value of these natural assets. Montero et al. (2019) estimated that when combining the economic and financial values of these resources, the actual cost of the illicit trade in flora and fauna has a global economic value of between US\$1 and US\$2 trillion per year.

Contrary to popular belief, the targets of crime are not limited to exotic and iconic species, such as elephants and tigers, but also include farmed produce including livestock and crops (e.g. livestock theft/rustling, sheep

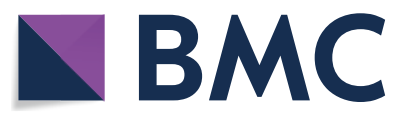

(c) The Author(s) 2021. This article is licensed under a Creative Commons Attribution 4.0 International License, which permits use, sharing, adaptation, distribution and reproduction in any medium or format, as long as you give appropriate credit to the original author(s) and the source, provide a link to the Creative Commons licence, and indicate if changes were made. The images or other third party material in this article are included in the article's Creative Commons licence, unless indicated otherwise in a credit line to the material. If material is not included in the article's Creative Commons licence and your intended use is not permitted by statutory regulation or exceeds the permitted use, you will need to obtain permission directly from the copyright holder. To view a copy of this licence, visit http://creativeco mmons.org/licenses/by/4.0/. The Creative Commons Public Domain Dedication waiver (http://creativecommons.org/publicdomain/ zero/1.0/) applies to the data made available in this article, unless otherwise stated in a credit line to the data. 
worrying and coursing). Crimes involving farmed produce in particular is an increasing problem for developing and developed countries alike, where agriculture forms one of the main contributors to both local and national economy through natural assets and exports (Donnermeyer and Barclay 2005; Swanson 1981). The fundamental role of agriculture globally means the impacts of crime involving farmed produce are widespread and affect stakeholders from 'field to fork'. The National Farmers Union (NFU) Mutual, one of the leading insurers of farms in the UK, estimates the cost of rural crime in the UK at GBP£49.9 M in 2018, with Livestock crime (LC) alone costing GBP£2.5 M (Sidebottom 2013; NFU 2019; 24th PANIU 2015a, b).

Various stakeholders, from individuals to governments, are involved in tackling the issue of wildlife crime and spend significant sums of money on programs aiming to protect species.

A review of donor funding of the Global Wildlife Program, a partnership of organisations led by the World Bank, identified that since 2010, funds of around US\$1.3 Billion were pledged to tackling wildlife crimes internationally. Beyond international conglomerate donations, collaborations such as the Wildlife Crime Initiative (WCI) between WWF and TRAFFIC, aim to tackle wildlife crime by engaging with local, national governments, charities and NGOs to deter the continued exploitation and extinction of species (UNODC 2017; WWF 2017; UN News 2016).

For all stakeholders there exist pragmatic questions about what problems to focus on, and what approaches and interventions to invest in. To ensure that the programs implemented are cost effective and produce no or limited negative consequences, decision-makers must also be aware of the likely impacts of different crime prevention techniques. However, the range of crime prevention techniques is large, varying from the use of a padlock on a barn door, to international legislation regulating trade in specific products. The variety of techniques employed, and the fidelity of implementation achieved, hinder the ability to estimate the effectiveness of programs on a macro-scale. This is illustrated by the example of the use of policy in order to prevent the trafficking of illegitimate goods. Establishing the impact of legislation and policy on an international scale, whilst accounting for the influence of local projects and schemes, would be major task.

An article by Kurland et al (2017) provided the first, and to the authors' knowledge, only overview of prevention methods used in conservation and wildlife crime prevention. The Kurland et al (2017) article recognised the importance of providing stakeholders with guidance on what prevention methods exist in the hope this would lead to more informed and effective decision making. The article has, however, two important limitations that are addressed in the present study:

The first limitation is that Kurland et al (2017) combined literature from the fields of conservation and crime prevention. Whilst both research areas relate to species protection, and the conservation field is likely to provide the majority of information of interest to this study, conservation techniques are not used solely to address illicit activities against species. The Kurland (2017) study tried to identify articles where the methods used mirrored those of SCP. A combined review of prevention techniques used to alter legal and illegal activities, requires a clear distinction between the different methods and/ or mechanisms by which the techniques work (e.g. increased penalties for illegal activity vs. education of the impact of legal but destructive activity). Assessing the effectiveness of the techniques used, becomes even more complex, as the driving forces behind situational crime prevention techniques may not be directly applicable when addressing non-criminal activity (e.g. removal of excuses using signs/rules may not be suitable if the activity is legal, despite its negative impacts on species). It is not possible to determine the significance of this limitation without more details about the searching and filtering methods used in Kurland's review.

The second limitation was identified by Kurland et al (2017) themselves. Whilst the method for the selection and filtering of articles was described, there was limited information relating to inclusion and exclusion criteria or an extraction framework. In concluding their review, Kurland et al (2017) commented on the benefits of completing a more systematic review that could provide a comprehensive understanding of the mechanisms, contexts and outcomes of assessed prevention methods (Petticrew 2001).

The purpose of this article is to assess the effectiveness of existing Situational Crime Prevention (SCP) techniques for the prevention of crime against species. It aims to complement Kurland et al's work and address the lack of research into what works in the prevention of species crime. Our work focuses on the measures implemented for the situational prevention of crimes against 'Terrestrial Species' (TS). Species is the term used as a principal taxonomic unit that denotes a 'group of organisms of similar individuals which are able to interbreed' (Larkcom and Delpech 2013). Species fall into one of five Kingdoms: Plantae, Animalia, Fungi, Bacteria, and Protoctists. During the scoping phase of this review, the authors acknowledged that movement on and around areas of water and shorelines introduced additional variables (e.g., theoretical offshore boundaries vs. physical on land boundaries; freedom of movement on and around 


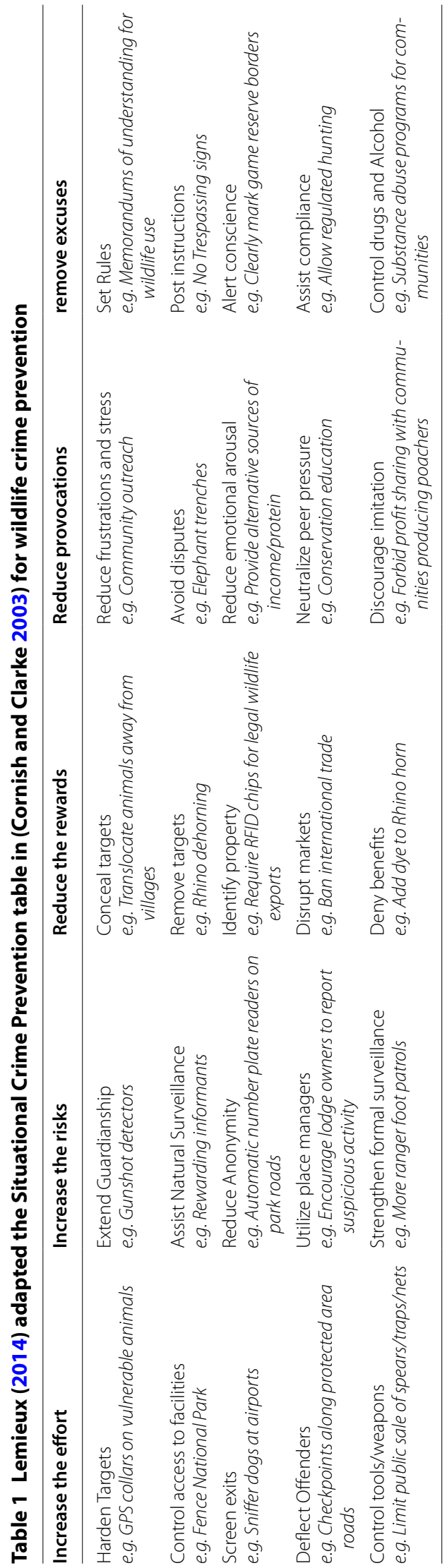


these areas, modes of transport), and due to the reviews already broad search strategy, it was decided that the aquatic environment, including marine and other aquatic species, and their associated crime prevention methods would not be included in this review. The authors recognise that this area is deserving of its own independent systematic review, and could be combined with the review of terrestrial species crime prevention methods in future (Larkcom and Delpech 2013). Microscopic species (e.g. protozoa, algae) were also excluded. The terrestrial species in the remaining Kingdoms of Animalia (other than Humans), Plantae and Fungi were included, and hereafter will be collectively referred to as 'Terrestrial Species'.

TS can be divided into two main groups (Driscoll et al. 2009):

- Wild species: native fauna and flora of a region e.g. elephants, tigers, bluebells, orchids.

- Farmed (domesticated) species: kept \& bred/raised and used as assets e.g. cows, chickens, wheat, ginseng.

The decision to combine information on prevention methods relating to wild and farmed species was made because many TS are categorized as both wild and farmed, depending on the given habitat-e.g. ginseng can be found in the wild but is also farmed in many countries (Daerr 2001). In addition to a categorical overlap, there also exists a geographic overlap, where the environments wild species inhabit are increasingly being used for agricultural purposes. The review assessed the effectiveness of prevention techniques used in rural areas. Rural areas were selected again due to the overlap between the agricultural landscape and areas where wildlife inhabit. The authors also acknowledged the differences in the physical structure, level of surveillance, and opportunities of rural and urban areas making the comparison or transfer of prevention techniques used potentially incompatible.

Beyond the categorical and geographic similarities between TS, there exists a shared aetiology in the crimes that affect them: TS are targeted for financial gain, subsistence and/or sport, which could mean that prevention techniques used for wild species may be transferable to farmed species and vice versa.

The contextual information of a given location is used to select or design suitable interventions that may increase the risks and effort required by the criminal, reduce the rewards and provocation and/or remove excuses, as perceived by offenders (see Table 1). A group of strategies used at a local level are collectively referred to as Situational Crime Prevention (SCP) techniques. Whilst all of the SCP techniques are potentially effective in preventing crime, they are not all suited to every given situation. For this reason, it is important to establish 'What Works' in relation to given types of crime, in this case crimes against species.

The absence of literature advising stakeholders as to what works best in preventing crimes against species, could increasingly lead to the poor investment of the already limited funds to tackle criminal activity involving vulnerable species internationally. A systematic review of the existing literature should provide stakeholders with an initial overview of what information is available, what methods have been evaluated and what works in preventing crimes against species. Researchers can use systematic reviews to identify the gaps in the literature, and undertake more outcome evaluation studies for future reviews.

\section{Method}

\section{Inclusion and exclusion criteria}

The systematic review was performed using the following criteria:

- Date of Research Publication-No exclusion criteria. The research must have been produced prior to September 2016 when systematic searching began.

- Published and Unpublished Research-A comprehensive search of the available literature was performed, including unpublished 'grey' literature, to mitigate the effect of publication bias (Mlinaric et al. 2017).

- International Literature-There was no restriction on the countries from which publications originated, but they must have been written in, or be available, in English.

- Intervention Type-Interventions included were deemed to be in line with the core situational crime prevention (SCP) techniques; i.e., those aiming to influence the perceived effort, rewards and risks of committing crimes, as well as removing the provocations and excuses associated with criminal behaviour (Cornish and Clarke 2003). Situations, and by extension situational crime prevention measures, exist throughout the crime commission process (Cornish 1994). From a poacher's perspective, for example, they may be found in the wild where animals live but also in villages where accomplices are briefed, tools prepared, and meat sold (Lemieux 2020).

- Intervention Type-The interventions examined in the identified studies were included if situational crime prevention techniques have been implemented and an outcome evaluation conducted, therefore, theoretical or 'proof of concept' studies (e.g. Borrion et al. 2019) were not selected for analysis. 
Literature relating to international or national policies such as those published by NGOs and governments are not included in the review, as literature relating to policy has insufficient data for assessment to establish its effectiveness on species crime prevention (Pires and Moreto 2011).

- Study Type-Interventions used to specifically reduce the incidence of crime against species were included in the review. Interventions that may have indirectly had a positive impact on the incidence of crimes against species or species numbers were not included. This is because the knock on effects of interventions can be difficult to evaluate, especially as changes in species numbers can be attributed to a variety of factors that go beyond crime, including land use changes, sustainable development and legal hunting.

- Location: Rural Areas-Studies explicitly described as occurring in an urban setting were excluded. The terms used in primary research to describe rural areas vary greatly, and included forest, farmland, agricultural land, national park, area of outstanding natural beauty, area of scientific interest, and village. Due to this variety of terms, and to avoid the exclusion of relevant articles, articles that did not specify a particular location, and those using generic rural terminology were automatically progressed to the next screening stage, if they met the other inclusion criteria.

\section{Search strategy}

The following search engines were used:

General Databases: International Bibliography of the Social Sciences (IBSS); ProQuest; PsychINFO; Scopus; Web of Knowledge; Zetoc.

- Agricultural / Environmental: AgEcon Search which covers research in Agricultural and Applied Economics-It is a free, open access repository of full-text scholarly literature on agricultural and applied economics; RSPCA-Wildlife Centre Research

- Criminological Databases: Australian GovernmentInstitute of Criminology; COPAC-UK Library Catalogue Database; National Criminal Justice Reference Service (NCJRS).

- Grey Literature Databases: British Library EThOS; System for Information on Grey Literature in Europe (SIGLE).

In addition, the following journals were hand-searched for relevant studies: American Society of Agricultural and Biological Engineers (ASABE); Crime Prevention \& Community Safety; International Journal of Agricultural Management; Journal of Applied Ecology; Journal of research in crime and delinquency; Journal of Rural Affairs; Proceedings of the Royal Society of London: Biological Sciences; Rural Sociological Society; Southern Rural Sociology; Understanding and managing threats to the environment in South Eastern Europe. As were the following books: Crime \& Conflict in the Countryside; Situational Prevention of Poaching; Crimes Against Nature: Environmental criminology and ecological justice.

Keywords for Boolean Searches-The search terms chosen were based on broad keywords that could be associated with species crime from animal type to prevention methods:

Search Terms were separated into three categories:

\begin{tabular}{ll}
\hline 1st: Livestock, Animal, Wildlife, Species, Plants, Crops & AND \\
2nd: Crime & AND \\
3rd: Intervention, Prevention, Reduction &
\end{tabular}

\section{Filtering Stages}

Initial article filtering was achieved by reading article titles and abstracts for relevance (as denoted by the inclusion/exclusion criteria described earlier). EPPI Reviewer software was used to manage the inclusion/exclusion process and the collation of relevant studies. A hierarchy

\section{Table 2 Hierarchy of exclusion for filtering the results of the database searches}

THEME $\begin{aligned} & \text { The title/abstract of the paper must clearly identify its relevance to the prevention of crime against species (e.g. poaching, theft, illegal } \\ & \text { trade) } \\ & \text { GEOGRAPHY }\end{aligned}$
$\begin{aligned} & \text { The title/abstract must not indicate a location that is exclusively urban (e.g. urban area, town, cities). If the title/abstract did not specifi- } \\ & \text { cally indicate a location it was progressed to the next stage }\end{aligned}$
$\begin{aligned} & \text { INTERVENTION } \\ & \text { The title/abstract must have referred to specific interventions for the situational prevention of crime against species } \\ & \text { Aquatic (e.g. coral, fish) or microscopic species (e.g. protozoa, algae) were excluded. Humans did not qualify as targets of crime in this } \\ & \text { review }\end{aligned}$


of exclusion is shown in Table 2 and includes: Theme, Geography, Intervention and Species.

Articles that were considered ambiguous based on their abstract and title were progressed to the second filtering stage, and read in full to prevent the loss of relevant studies in the filtering process.

\section{Quality assessment and data extraction}

A data identification and extraction document was developed in line with examples used in previous systematic reviews as described on the Cochrane \& Campbell systematic review website, and in line with the EMMIE framework. The document was used to standardise the extraction of relevant information from the articles being reviewed. Additional subfields were included in an iterative process to address when new aspects emerged during the initial stages of reading and assessing the information available in the filtered articles. Reasons as to why articles were not progressed were also recorded for reference.

The EMMIE framework was used to organize the synthesis of information extracted from the final included studies (Johnson et al., 2015). Rather than focusing exclusively on the effect size of interventions, the framework was developed to emphasise the need to explicitly synthesise (and assess the quality of research concerned with) what is known about other important dimensions of interventions that are relevant to policy-makers and other stakeholders. The five dimensions of EMMIE are: Effect, which considers the size of the impact of an intervention; the Mechanisms through which an intervention is believed to bring about its intended effects; the contextual Moderators that may influence the likelihood that an intervention has its intended effects; the key aspects of Implementation that are required for the delivery of the intervention; and, the Economic costs and benefits associated with the intervention. As well as synthesising what is known, the aim of the framework is to help explicitly identify gaps in knowledge.

\section{Results and Discussion}

Figure 1 illustrates the stages of document screening and shows that, of the 29,252 articles initially identified, only five remained after the application of the study criteria.

Research on species crime often combines unknown volumes of criminal activity and unknown populations of species, creating a complex field of research, where the methods adopted are the best fit for the data available, rather than those with the greatest internal validity.

Of the five studies that met the inclusion criteria, one examined the impact of community outreach, while the remaining four examined the impact of anti-poaching patrols. Outreach programmes have been included as they have direct relevance to the five situational crime prevention principles (e.g. "aimed to build trust, raise awareness, motivate, offer opportunities for action, increase perceived behavioural control of villagers and generate social pressure against poaching"). Anti-poaching patrols have also been included as they are equivalent to 'security guards', one of the 25 situational crime prevention techniques.

In what follows, given the limitations in the data available, the two interventions identified, and the analytic methods used in the primary studies, the overall findings for each type of intervention are presented in the form of a narrative synthesis, following the basic structure of the EMMIE framework.

\section{Community outreach}

A study by Steinmetz et al (2014) assessed the effectiveness of a community outreach intervention. The situational crime prevention technique employed by the community outreach team was aiming to remove the excuses used by locals, by educating them of the impact of the illegal activity involving the species. This was implemented between 2008 and 2011 in Kui Buri National Park, Thailand. Over the four-year period 116 outreach events were ran which reached approximately 7500 people across 24 villages. The outreach work was estimated to have covered $83 \%$ of villages within $5 \mathrm{~km}$ of the park, with some visited more than once. The outreach programme aimed to build trust, raise awareness, motivate, offer opportunities for action, increase perceived behavioural control of villagers and generate social pressure against poaching. The mechanisms identified by the authors as to how the community outreach was expected to have had an effect are directly related to the situational crime prevention principles, particularly raising awareness, increasing perceived behavioural control and generating social pressure. The results of the study suggest that species crime has reduced as a result of the outreach programme.

\section{Wildlife abundance over study period}

The wildlife populations of four species at three sites $(4$ species $\times 3$ sites $=12$ measurements) were monitored using observation surveys conducted annually from 2006 to 2011 (in the dry season: November to June) at three sites (each being $30-50 \mathrm{~km}^{2}$ ). The surveys revealed that three of the monitored species increased significantly: Pig occupancy almost doubled at Klong Kui $(\mathrm{p}=0.034)$, Muntjac roughly trebled $(\mathrm{p}=0.018)$ and Pig increased by roughly half at Hup Inthanin $(\mathrm{p}=0.045)$, other species such as Gaur in Klong Kui were nearly extinct from the area but began repopulating. Whilst the increase in Gaur occupancy was not statistically significant $(p=0.17)$, it was an important positive outcome for the local area 

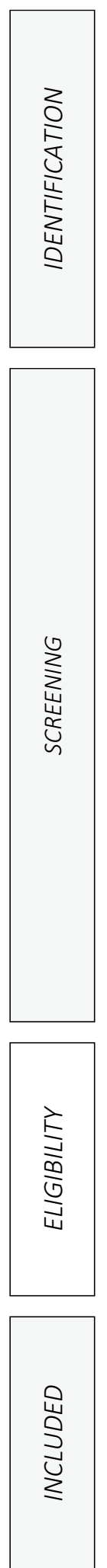

Initial Article Search Total: 103,162

After removing duplicates: 29,252

The remaining articles were retained for screening on the title and abstract.

Initial screening of the title and abstract of articles returned:

$$
119
$$

These articles warranted full text assessment of eligibility to be included in the final synthesis.

Full text assessment of articles:

$$
123
$$

Articles assessed using inclusion/ exclusion criteria (see methods).

Total includes four additional articles identified by backward searching but were subsequently excluded.

\section{Articles Included in final synthesis:} 5

Four articles assessed the effectiveness of anti-poaching patrols.

One article assessed the effectiveness of community outreach.

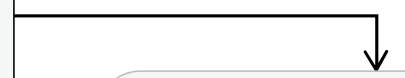

Excluded on Theme $=$ 28,905

Articles not related to crime against species were excluded.

Excluded on Geography = 4

Articles related to urban areas were excluded.

\section{Excluded on Intervention =} 186

Articles not related to SCP interventions were excluded.

Excluded on Species = 38

Articles not related to specified species were excluded.
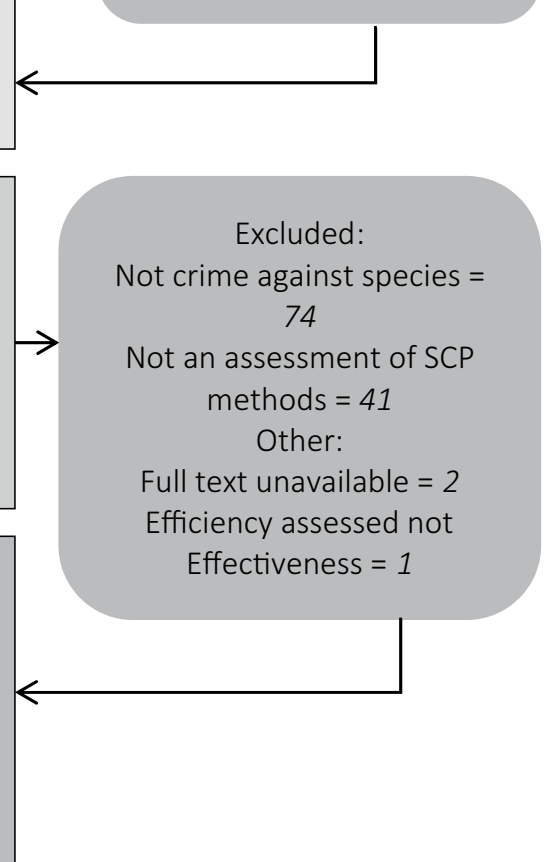

Fig. 1 The process used to filter and assess articles 
with the repopulation of the species. The only species to see a decline was Sambar, which was stable at Hup Inthanin but declined in the two other monitoring sites. This decline was, however, not considered statistically significant $(\mathrm{p}>0.07)$.

Camera trapping was incorporated into the study to complement the occupancy surveys. Cameras were placed in 25-28 locations in 2007, 2009 and 2011, in a $130 \mathrm{~m}^{2}$ that encompassed two of the occupancy survey areas. The image results corroborated the survey findings, with estimated increases in species numbers identified over the study period for Pig $(p=0.007)$, Porcupine $(p=0.037)$ and Gaur $(p=0.002)$, for which the numbers nearly doubled. For the Muntjac $(p>0.28)$ and Sambar $(p=0.086)$ the numbers were found to be stable.

\section{Poaching pressure over study period}

Poaching pressure was calculated using the encounter rate of poaching signs (shotgun shells, tree stands, snares, carcasses, hunting camps) per $100 \mathrm{~km}$. Poaching pressure declined by fourfold $(\mathrm{p}=0.059)$ between 2009 and 2011, reducing from 10.1 hunting signs per $100 \mathrm{~km}$ in 2009, to 6.8 in 2010, and finally 2.4 in 2011.

The authors conducted two analyses to assess the influence of existing patrols on the observed decrease in poaching pressure and increase in wildlife abundance: (1) Deterrence effect of patrolling on poaching pressure-whether any changes in poaching pressure were the result of the established anti-poaching patrols in the study area the previous month, (2) Effect of patrolling on wildlife trends-patrol effort was used in and around the three wildlife monitoring sites; patrol effort was used as the predictor variable, and the wildlife occupancy trends as the dependent variable.

Two additional analyses were carried out to verify that the observed decrease in poaching pressure and increase in wildlife abundance were due to the outreach campaign: (3) Effect of intensive outreach on poaching-from June to November 2010, outreach events were held in close succession next to eight patrol zones allowing the authors to examine the effects of intensive outreach by looking at patrol effort and poaching data between two periods before and after outreach work took place, and (4) Effect of outreach on poaching, as perceived by locals-multiple choice questionnaires were used to elicit the opinion of locals as to levels of poaching before and after the outreach work took place. The results of these analyses are presented below:

\section{Patrolling effects on poaching pressure and wildlife abundance}

To account for existing patrolling the authors assessed the influence of patrolling on the reduction in poaching over the same period of time the outreach work was conducted. No correlation was found between patrol effort and poaching pressure $(\mathrm{p}=0.43)$. There was also no relationship between annual patrol effort and the mean occupancy trends of the monitored species in the same year $(p=0.532)$ or subsequent years $(p=0.792)$. Note: there was no significant difference $(\mathrm{p}=0.10)$ in the mean monthly patrol effort per zone in 2009 (1.7 days), 2010 (0.94 days) and 2011 (1.2 days). Patrol effort was not found to differ significantly before and after the intense outreach campaign $\left(\operatorname{median}_{\text {before }}=1.0, \operatorname{median}_{\mathrm{after}}=1.7\right.$, $\mathrm{p}=0.161)$ either.

\section{Outreach effects: deterrence effect of intensive outreach on poaching}

To examine the short-term spatial effects of intensive outreach, the authors used patrol effort (mean number of patrol days per month) and poaching index data (number of poaching signs per $100 \mathrm{~km}$ ) and tested whether differences existed in the months prior (7 - 19 months) and post ( $2-8$ months) the outreach campaign. As explained above, patrol effort was not found to differ significantly before and after the intense outreach campaign. However, poaching was found to decline after the outreach campaign $(\mathrm{p}=0.017)$ with a median number of poaching signs per $100 \mathrm{~km}$ falling from 4.7 to 0 .

\section{Outreach effects: perceptions and attitudes questionnaire}

Of the 7500 members of the community estimated to have been involved across the 12 areas where community outreach had been conducted around the park, 311 adults completed a survey to assess their perceptions of poaching related behaviours (consumption of wildlife, sale of wildlife within village, sale to outsiders, hunting by villagers, hunting by outsiders, hiring of villagers to hunt by outsiders), the overall poaching trend over the last 5 years (covering the time of the outreach work), and nine potential causes for change in poaching trends (park patrolling, park outreach, wildlife abundance, market demand, number of hunters, time available for hunting, income, conservation awareness, interest in consuming wildlife). Finally, respondents were asked about their attitude towards wildlife recovery (support, oppose, indifferent). Most respondents indicated that they had perceived a decline in the six types of poaching behaviours, with $88 \%$ believing that there had been a decline in poaching overall. The survey respondents were asked what contributed to this perceived decline in their view: 'Increased park outreach' was the main answer (67\% of the locals), followed by 'increased patrolling' and 'conservation awareness' (61\%).

In summary, the results suggest that a decline in poaching behaviour occurred, with the locals believing 
the outreach work was the main reason for this decline. In addition to the outreach work, locals also believed increased patrolling (despite data indicating no significant change in patrol effort before and after the outreach work) and increased conservation awareness (indirect benefit of building stronger relationships between park staff and the local community through the outreach work) had also been influential on the decline in poaching.

\section{Mechanisms}

The authors presented outreach participants with three ways in which they could positively impact the occurrence of poaching locally: (1) educate other community members on the issues facing local wildlife, (2) curb their own hunting and consumption of wildlife, and (3) ostracizing/inconveniencing those involved in poaching.

The central mechanism to explain how community outreach activities would prevent specific crimes against species, involves tackling neutralisation and removing excuses. Neutralisation is a psychological approach to distance oneself from acting contrary to social norms and personal values. Neutralisation techniques include denial of injury, denial of victim, and condemnation of condemners (Sykes and Matza 1957). One of the most common neutralisation techniques associated with criminal behaviour is the denial of responsibility. An individual will define a situation in a way to relinquish personal responsibility for their behaviour or actions. By using community outreach to educate individuals about the impact of poaching, including the direct and indirect effects of their actions, the intention of the intervention was to make it harder for some individuals to utilise neutralisation techniques to appease their conscience, in relation to species crime.

By removing some of the excuses associated with species crime, such as ignorance of the impact, or belief that no other opportunities exist, the individuals involved come under increasing pressure both from their local community and their own morality to desist in taking part (Maruna and Copes 2005).

\section{Moderators}

The following moderators were identified as factors that could influence the outcome of community outreach schemes designed to protect species:

\section{Access to other alternative livelihood opportunities}

Recognition of the location specific context is important when considering the likely impact of any intervention. The villages concerned had an agricultural base which many poachers could turn to for work and food. However, the authors admitted not all individuals associated with poaching will have alternative means of income available and, therefore, outreach work would have a variable impact (Cooney et al. 2017). The identification of alternative livelihood opportunities is thus important to consider when implementing such interventions.

\section{Target Audience}

The authors reflected on historical outreach work from other fields and focused significant amounts of educational outreach at schools and towards children, hypothesising that the children would then relate this information to their parents and thus use social pressure to encourage positive behaviours. They did not measure the perception of the social-psychological processes used and therefore could not attribute the behaviour changes observed to any one aspect. However, social pressure seems to have played a large role in the change in poaching over the study period. By targeting audiences with greater outreach potential such as local leaders, park staff and children, the authors attempted to maximize the impact of the work being undertaken.

\section{Number of poachers}

The authors of the study referred to research in SouthEast Asia, where only a minority of the local population were involved in poaching. This meant there was significant social pressure from those not involved in poaching. Future research should assess whether the outcomes of outreach activities will be more limited where there is greater proportion of the community involved in poaching.

\section{Implementation}

The community outreach work required researchers to work in conjunction with the local government agencies and NGOs to connect with and obtain the permission of local chiefs to reach a large number of community members. Steinmetz et al (2014) targeted six social or psychological conditions to create behavioural change: Trust, Justification, Motivation, Ethical, Feasible Actions and Confidence.

The first four issues were dealt with through face-toface interactions with locals, providing them with education and evidence of the importance of preventing species crime and explaining the benefits and responsibility of locals in maintaining healthy environments and species numbers.

The outreach work was conducted by $6-10$ park staff, as well as the authors, who held events including those at village meetings, schools, temple fairs, youth camps, and 2-3 h government meetings. The outreach sessions were interactive and included 10-20 min presentations, a quiz with prizes, a Q\&A session, and musical performances 
by the park ranger band. Between 2008 and 2011 the researchers and park staff completed 116 outreach events. School based events also included additional games and encouraged students to create 'wildlife recovery plans' which detailed actions students could take to help wildlife. The education of locals was supplemented by suggesting feasible actions to change the incidence of poaching in their local area, and by providing locals with the confidence to control their environment.

\section{Economics}

The associated costs of the Community Outreach Scheme were not described in this study.

\section{Summary}

Community outreach is increasingly used to tackle security problems internationally, with schemes such as Neighbourhood Watch, Farm Watch and others, being actively used to encourage the community to take responsibility and preventative action against crimes in their local area (What Works 2015). Community outreach in relation to crime is not limited to developing countries or rural areas: many schemes simply aim to increase the awareness of illegal activity amongst local people, and to build community bonds which encourage intervention by locals when crimes are witnessed, or the provision of information on illicit activity to the authorities. The intervention tried to promote responsibility and awareness of the impacts of species crime. The findings suggest that, with sufficient intensive outreach work, involving gaining the trust of influential members of society (e.g. local leaders), educating the local people about the negative impact of illicit activities, and advising locals of alternative livelihoods to illicit activities, can contribute to the reduction in species crime. However, with data only available from one study (which did not have an untreated control site), further evaluation research is clearly necessary to determine whether the impacts reported are replicable and, if so, whether they are context specific.

\section{Anti-poaching patrols}

The four remaining articles examined the effectiveness of anti-poaching and protected-area patrolling. Patrols for the prevention of species crimes such as poaching, typically involve rangers/soldiers moving through protected areas usually on foot, searching for poachers or poaching paraphernalia (Moreto et al. 2014). The situational crime prevention technique employed in these studies was equivalent to the use of Security Guards, with the aim being to increase the perceived risk associated to committing crimes against terrestrial species by strengthening the formal surveillance in the study area/s.
The studies reviewed used quasi-experimental methods, where a control group may not exist, or if it does, it may not receive the same experimental treatment as the treatment group. Several of the studies combined the results with qualitative information collected through interviews or surveys of stakeholders. The variability between areas (e.g. accessibility, terrain, target species, socio-political factors), and patrols (e.g. methods, resources, rangers) make it difficult to plan and execute 'gold standard' experiments such as randomised control trials. Moreover, most of the studies conducted have relied on historical data, which makes randomization impossible.

The targets of such crimes were some of the most iconic species associated with poaching across Africa and Asia, including elephants, rhinos, buffalo and tigers. All of the included studies (shown in Table 3 and 4) concluded that anti-poaching patrols in their various forms were effective to varying degrees, in altering the prevalence of species crime.

\section{Study 1}

Hilborn et al. (2006) estimated the effectiveness of patrolling in the Serengeti National Park using three datasets recorded over several decades (see Table 3). In 1977 Tanzania's economy declined and cuts to the park budget meant that poaching was believed to have increased. In the 1980s the park budgets increased, which allowed park staff to resume patrolling activities. Hilborn et al. (2006) reviewed historical datasets that suggested poaching declined, and species populations improved or recovered when anti-poaching funds were made available, and patrolling was actively implemented in the National Park.

The census of Buffalo abundance was used as an indicator of poaching intensity. A simple population dynamics model illustrated that between 1955 and 2005, the variations in buffalo numbers could be accounted for by changes in poaching behaviour, which in turn could be accounted for by the changes in patrolling effort.

Whilst this study covered the longest time period, it provided minimal details relating to the patrols (as shown in Table 3) and did not account for confounding variables that may have contributed to the variation in poaching and patrolling levels. Overall this study provided the lowest quality assessment of the effectiveness of patrolling as a preventative technique, but it relied on historical data, which perhaps explains this.

\section{Study 2}

Leader-Williams et al. (1990) conducted research in Luangwa Valley in Zambia on the anti-poaching patrols aimed at combating the poaching of elephant and rhinos. Their findings corroborate those of Hilborn et al. 


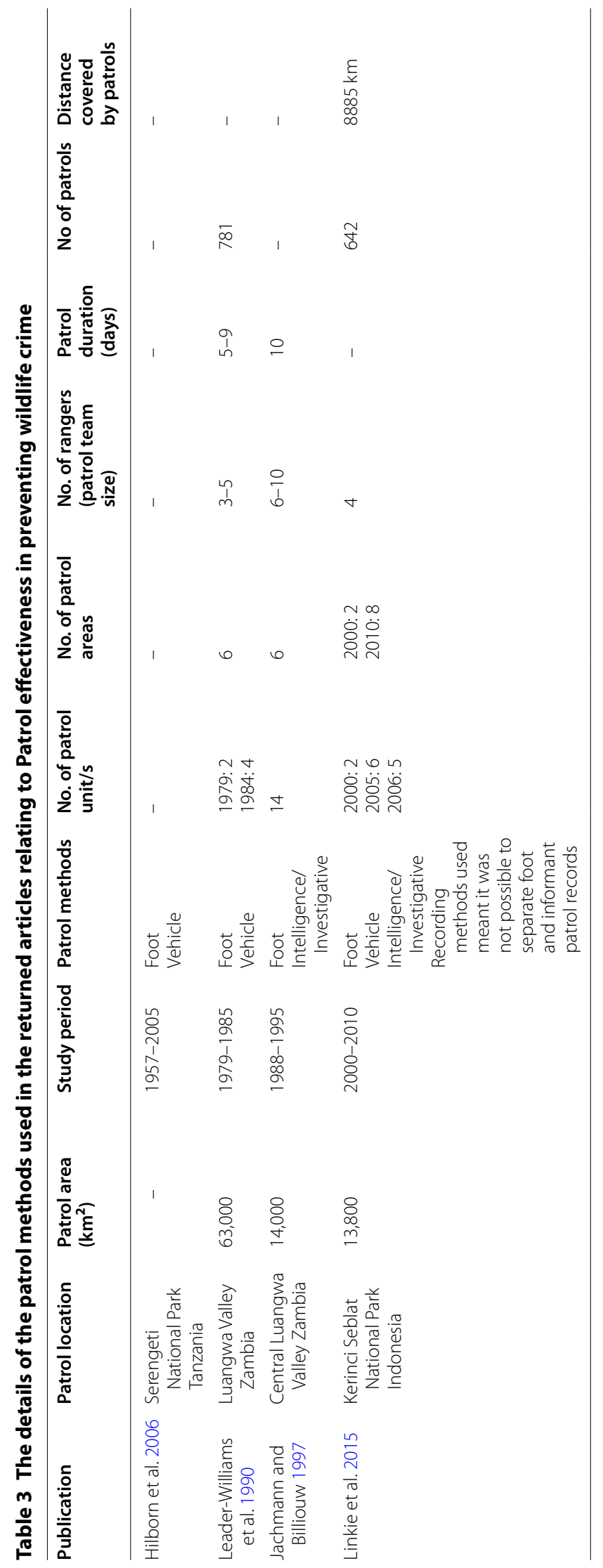




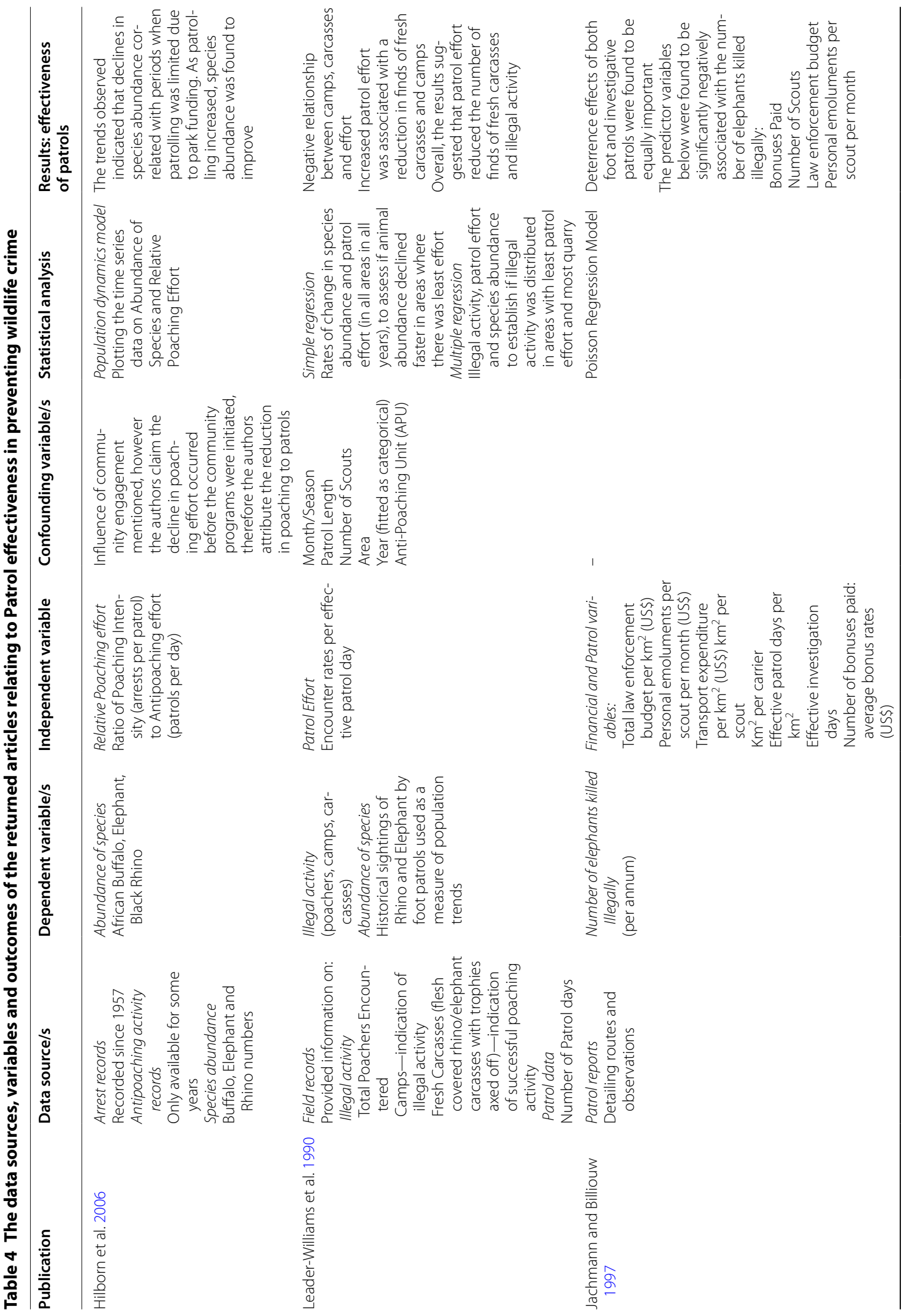




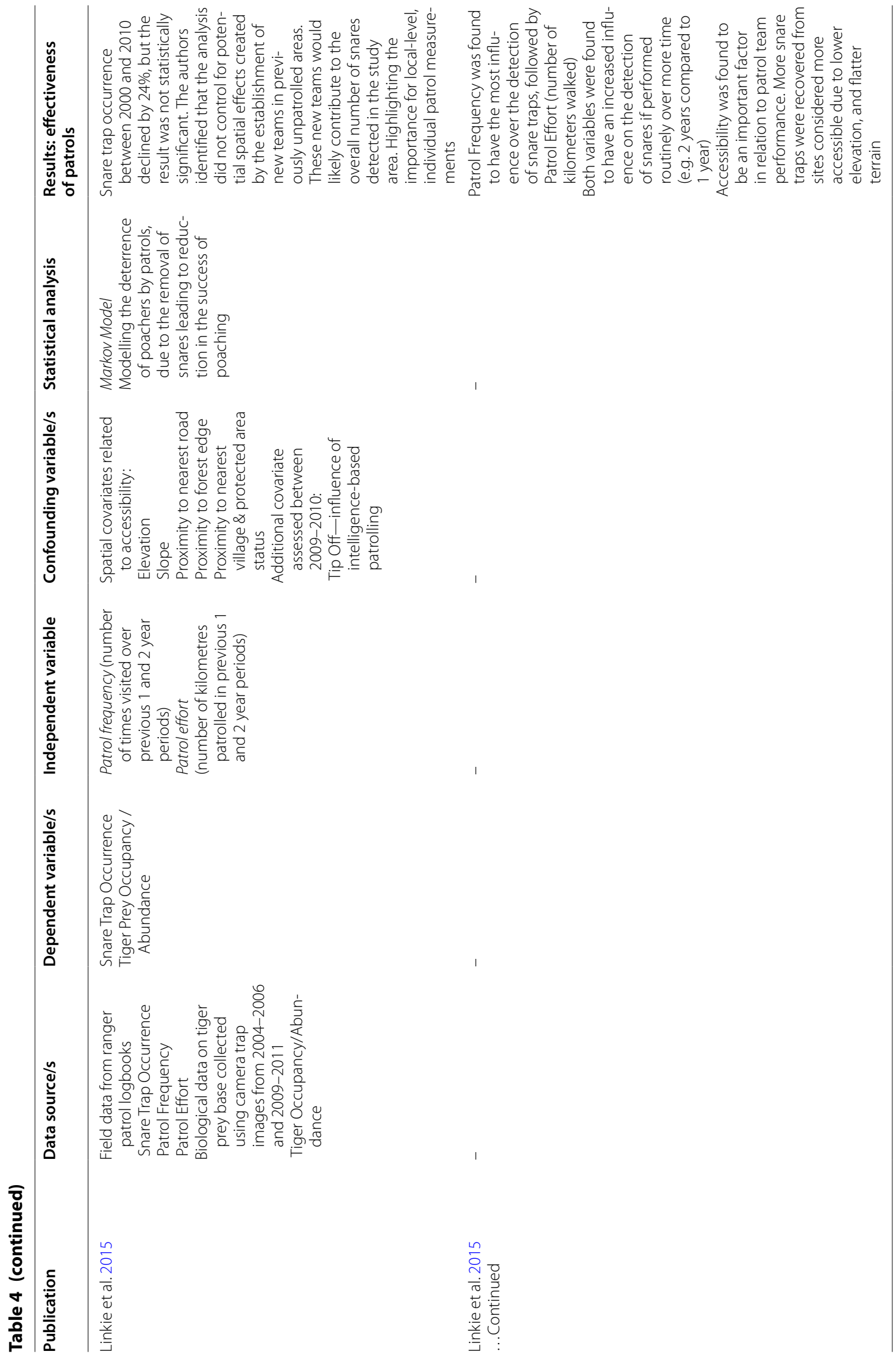


(2006), also suggesting that the presence of patrols were associated with a deterrent effect on poaching. Data was derived from 781 foot patrols conducted between 1979 and 1985, using evidence of elephant and rhino sightings as well as the detection of skulls/trophies witnessed by rangers. Patrols were made up of three to five scouts, and varied in duration between a few days to several weeks, with an average of 5-9 days per patrol.

This study examined various indicators of illegal activity (including carcasses, camps and poachers apprehended) as well as a number of other covariates (shown in Table 4), with the analysis being one of the most robust assessments of effectiveness of the identified studies.

The study identified that the observations of elephant abundance and subsequent changes in this value, were a composite measure of loss due to illegal activity and local immigration/emigration, which could not be quantified separately. Due to this, the authors could not definitively conclude that the number were representative of the relationship between patrolling and elephant abundance but could conclude that the patrolling provided the elephants with a safe haven that other elephants moved into.

In contrast to elephants, rhinos were not found to move to areas of increased safety, and therefore their abundance values were considered to be representative of the species and any losses.

The authors identified that between 1979 and 1985 there was a decline in elephant and rhino numbers in the Luangwa Valley. However, this decline in numbers was identified as not being the result of a lack of motivation by patrols, but instead was more likely the result of insufficient numbers of patrol officers to cover the size of the National Parks in Luangwa Valley.

Patrols were found to be effective where they were implemented with sufficient manpower. Foot patrols and vehicle patrols were found to catch large numbers of offenders over the study period. In these locations, patrol effort was found to have a reductive effect on the distribution of illegal activity and in turn increase the abundance of elephants and rhinos, with findings showing a negative relationship between patrol effort and the discovery of poaching camps or fresh carcasses (Elephants $\mathrm{p}=0.05$; Rhinos $\mathrm{p}=0.01$ ).

The authors of this study reiterate that the decline in species numbers in the Luangwa Valley is not reflective of the effectiveness of the patrols, as the existing patrols were found to be effective where deployed. The decline in species abundance is an indicator of the need for more patrols to cover the entirety of the Valley effectively.

\section{Study 3}

Linkie et al. (2015) researched the performance of antipoaching patrols in Kerinci Seblat National Park in
Sumatra that aimed to protect tigers and their ungulate prey. The research looked at foot patrols conducted between 2000 and 2010. The study was one of the most comprehensive studies (see Table 3) of patrolling effectiveness, measuring patrol frequency and patrol effort, snare trap occurrence, and species (tiger and prey) abundance (using patrol data and camera trap data).

Over the study period, the researchers reviewed 642 forest patrols (see Table 4) covering $8885 \mathrm{~km}$ during which time they removed 122 snares set specifically for tigers and 4311 traps set for the ungulate prey. Detection histories for each patrol year were used to calculate the snare detection probability between 2000 and 2010 .

Detection Probability is used in situations when total abundance cannot be accurately identified (e.g. counting animals in the wild or poaching paraphernalia). Detection probabilities allow researchers to account for unavoidable variability, by taking into account the number of targets detected, the number of visits to sites as well as allowing researchers to account for confounding factors that may make the target population change temporally or spatially.

The study showed a (statistically insignificant) decline in snare trap occurrence of $24 \%$, between 2000 and 2010 . However, the authors were unable to control for the influence the introduction of new patrols would have had on the overall number of snares detected in the study area.

The authors suggest that the reduction (albeit nonsignificant) in snare trap occurrence, combined with no significant changes in the occupancy of tiger prey species over this period, is indicative of the park's anti-poaching strategies contributing to a stable tiger and prey population. The frequency of patrols was found to have a greater impact on snare detection compared to increasing the distance covered by the foot patrols.

Patrols appeared to gain experience in detecting snares, shown in the detection probability increasing annually between 2000 and 2006 before plateauing.

The study incorporated several covariates relating to accessibility of the landscape to both poachers and patrols. Accessibility was found to be a key factor in snare detection. The more accessible areas require less effort to reach them and are therefore more practical target locations for both poachers and patrols.

Intelligence-based patrols were assessed for the period 2009-2010 in addition to the traditional foot patrols. Intelligence patrols used informant tip-offs, which significantly increased patrol effectiveness, when compared to ordinary foot patrols. The detection probabilities of intelligence-based patrols were $48 \%$ higher than foot patrols in 2009 and $41 \%$ higher in 2010. 


\section{Study 4}

Jachmann and Billiouw (1997) conducted research in Central Luangwa Valley in Zambia, into resource allocation and elephant poaching between 1988 and 1995. During the study period, 149 elephant carcases were discovered, with all but two having been killed for ivory. The results of Jachmann and Billiouw (1997) suggest that patrolling had a positive impact, preventing illegal activity relating to elephants. They also identified specific variables that appear to have influenced the efficiency and effectiveness of patrolling.

The authors looked at nine variables associated with resource allocation (see Table 3). The results of the study indicated that five of these had a significant effect on the number of elephant carcasses discovered. With respect to the discovery of elephants found killed illegally, effective investigation days $(\mathrm{p}=0.04)$, and scout density $(\mathrm{p}=0.04)$ were found to be significant predictors. So too were the number of bonus claims paid $(\mathrm{p}=0.003)$, personal salary per scout month $(\mathrm{p}=0.04)$, and Law enforcement expenditure per $\mathrm{km}^{2}(\mathrm{p}=0.05)$. Based on these findings, Jachmann and Billiouw (1997) recommend that stakeholders involved in species protection focus resources towards increasing the number of scouts/rangers and supporting the collection and rewarding of intelligence and informants.

\section{Mechanisms}

The two main mechanisms by which patrols are believed to affect poaching activity are increasing the perceived risks of being caught and the perceived cost of carrying out illegal activity.

\section{- Increased risks}

One of the core principles of the SCP framework involves increasing the (actual or perceived) risks of offending. Increasing the number, distance and size of patrols, therefore has the potential to act as a deterrent to those considering poaching. The rangers also used informal surveillance in the form of community informants, who reported poachers and poaching activity in their particular areas.

\section{- Increased costs}

The removal, confiscation and destruction of poaching paraphernalia (such as snares, weapons, vehicles, etc.) has a financial impact on those committing such crimes, which in turn can discourage their activity. If snares are removed by anti-poaching patrols repeatedly, the costs associated with replacing the snares may deter an individual from being involved in such crimes in future. Several studies mentioned that increased patrolling or patrolling in new areas could lead to displacement of poaching activity, where the poacher changes their spatial movements in an effort to avoid the patrols. However, displacement and its potential impacts was not investigated by any of the studies.

\section{Moderators}

Factors that influence the detection rates for patrols varied greatly between different patrol teams and over time. Moderating factors identified in the literature that could influence the outcome of anti-poaching patrols:

\section{- Accessibility}

Accessibility is an important factor in the spatiotemporal analysis of TS crimes, with locations being influenced in a variety of ways by natural features including terrain and vegetation, man-made features such as road networks, and potentially the political/ safety considerations of the areas being patrolled. Linkie et al. (2015) incorporated accessibility factors into their analysis of poaching and patrol effectiveness, and found it significantly influenced the likelihood of poaching and patrolling activity.

\section{- Ranger experience and ranger numbers}

The experience and number of rangers are considered influential factors in the efficiency of the patrols. The increase in number of rangers had an impact on number of patrols and coverage, both of which influence the likelihood of detection thereby having a positive impact on the effectiveness of patrols for the purposes of preventing crime against species. Linkie et al (2015) noted that over time the patrols increasing experience lead to an increase in the detection of snares.

\section{- Time spent patrolling}

Patrol variables such as time and distance, are related to the type of species being targeted. Jachmann and Billiouw (1997) noted that the number of effective patrol days was not a significant factor in the number of elephants killed. These findings contrast with those of Linkie et al. (2015) who found that the duration spent patrolling was the most significant factor for effective patrolling, compared to other factors such as distance patrolled. The detection of snares for tigers, as assessed in the work of Linkie et al. (2015), suggested that increased frequency of patrolling over long periods of time ( 2 years) had a strong influence on snare detection rates in the areas being patrolled. The variation in target (e.g. elephant carcasses, tiger 
snares, species of interest, poachers) is therefore likely to significantly influence the relevance of predictor variables.

\section{- Intelligence-led operations vs. foot patrols}

Jachmann and Billiouw (1997) assessed the detection rate of intelligence-led operations (based on informant information), as opposed to routine uninformed foot patrols. There results suggest that intelligence-led operations were more efficient than conventional foot patrols. In relation to arrests, one man-day of intelligence-led operations equated to 23 man-days of foot patrols. However, the costs (discussed later) of intelligence-led operations were 6 times higher than those for foot patrols. Therefore, intelligence-led operations were a factor of four better than routine foot patrols, in terms of the costs associated with arrests.

\section{- Target type}

Leader-Williams et al. (1990) discussed the difference in movement between elephants and rhino, with elephants immigrating/emigrating between areas. The variation in target type (e.g., elephant carcasses, tiger snares, species of interest, poachers) would impact patrol variables (e.g. time and distance) and subsequently the effectiveness of patrolling.

\section{- Bonuses and Incentives}

Jachmann and Billiouw's (1997) study was the only one to examine the influence of bonuses and incentives on the effectiveness of patrolling. Bonuses were found to have a significant effect on the number of elephants found killed. The use of financial incentives to encourage others to cooperate with patrols is controversial but was shown to be effective in this study.

\section{Implementation}

The search for evidence of criminal behaviour involves a variety of implementation stages and procedures. The studies identified in this review all retrospectively assessed the effectiveness of anti-poaching patrols. Information pertaining to patrolling such as number of rangers, distances travelled, and equipment used was limited or absent across the articles reviewed, which reflects the inconsistency and difficulties faced when using historical data (Hilborn et al. 2006).

\section{- Changes in data recording procedures}

What rangers observed during patrols was typically recorded on paper using maps to record the loca- tion of the incident they had intercepted. While technology for recording patrolling information has advanced (e.g. Global Positioning System (GPS) equipment can now be used to accurately log patrol routes), it is important to acknowledge that access to such equipment is not widespread, and therefore significant differences exist in the recording method for different areas. The rangers' awareness and ability to navigate new recording systems can impact the accuracy of recorded data. Variability in data recording can also have a significant impact on subsequent data analysis (Linkie et al. 2015).

Changes in the behaviour of rangers are unlikely to be quick, and this needs to be taken into account when analysing data, and estimating the relative 'success' of an intervention that may still be in the process of being fully integrated ten years after its first introduction.

\section{- Technological limitations}

GPS coverage can vary and may be limited in places covered by dense canopies or thick vegetation. Failure of equipment to automatically record ranger locations accurately will impact on the accuracy of the information recorded and any subsequent analysis (Martin 2013).

\section{Economics}

As previously stated, the specific financial costs of interventions are not commonly documented in primary research, and again there existed limited information to include in this section from the articles identified. Jachmann and Billiouw (1997) described some of the financial costs associated with patrolling, where cash rewards were offered for information on poaching and poachers, with arrests or recovered firearms/trophies receiving additional cash awards to compliment patrolling. The article describes the estimated costs associated with patrolling (including salaries and bonuses) and proposes that efficient patrolling could be achieved with a total enforcement budget (based on the given circumstances of the region) of US $\$ 50$ per $\mathrm{km}^{2}$.

Leader-Williams et al. (1990) conducted research in the same area as Jachmann and Billouw and provided estimates of cost-effectiveness. According to their estimates, between 1979 and 1985 spending on patrols equated to about US\$1.1 M. Over the same period, 1483 offenders were caught by four anti-poaching units. Taken together, they estimate that the cost per offender caught was US\$730, and they suggest that this was comparatively cheap when compared to other forms of 
law enforcement. Of course, the reviewed papers were published in the 1990s and the financial costs will have increased in the last 20 years, but the estimates provide a basis for estimating likely current costs.

\section{Summary}

Anti-poaching patrols are used to detect and deter the exploitation of species and natural capital found in national parks and rural areas internationally. Whilst a number of variables can impact the effectiveness of patrols such as terrain, weather, time patrolling, distance patrolled, investment in rangers and equipment, the overall findings suggest that anti-poaching patrols are effective in deterring poaching. However, the articles that assessed the effectiveness of anti-poaching patrols had a variety of data quality issues:

\section{Data quality issues: retrospective data and species population measures}

All of the articles identified had similar issues associated with the quality of the data available, and the methods employed given that the authors were limited to analysing largely retrospective secondary data. The issues encountered were as follows:

- Animal population-Estimating the population of a target species is fraught with difficulty, and due to this, it is impossible to accurately quantify the proportion of animals illegally killed; instead, researchers must assume that the detection of animals and poached carcasses provides a proxy measure of the poaching pressure or variation in animal abundance.

- Movement of animals-Calculations are complicated further by having to account for the emigration and immigration of animals into and out of the areas of interest.

- Poaching pressure-It is assumed that what is detected by patrols (camps, carcasses, poaching paraphernalia) is directly proportional to the poaching pressure in a given area. However, these figures only reflect the areas actually patrolled and hence provide only a partial picture.

- Patrol coverage-In relation to the patrolling of protected areas, most areas have little to no patrol coverage, and ranger patrols are not uniformly distributed. As such, accurate levels of crime prevention are difficult to estimate (Moreto et al. 2014).

Such issues need to be considered when reviewing articles on this topic and in future work.

The limited number and in some cases the age of the anti-poaching articles ( $>20$ years old) as well as the data quality issues described above, bring into question the quality of the articles, and would make it difficult to provide any definitive recommendations on the use of such a technique for the prevention of terrestrial species crimes. Further evaluation research is needed to determine whether current anti-poaching patrolling continues to show a positive effect in the reduction of poaching activity.

\section{Discussion}

Systematic reviews are used to bring existing empircal evidence together and identify 'What works?' This study is the first systematic review to the authors knowledge that has attempted to bring together all the available literature relating to the effectiveness of situation crime prevention techniques for the prevention of crimes against species.

Empirical evaluations are a valuable tool to inform resource allocation. However, the subfield of criminology that focuses on the causes of, and responses to, 'ecological', 'environmental' and 'green' crimes, harms and hazards, suffers from a lack of empirical quantitative studies (Lynch et al. 2017; White 2013). This systematic review confirms the severely limited amount of evaluations on the effectiveness of techniques for preventing terrestrial species crime.

The five articles identified in this review focused on the criminal activity of poaching, and reported on the effectiveness of two methods of situational crime prevention: increasing associated risks (anti-poaching patrols) and removing excuses (community outreach). A single study suggested that Community Outreach was found to be effective in reducing poaching, whilst the other studies provide evidence to suggest that Patrols can be effective, although the quality of the anti-poaching studies varied greatly.

The focus on the prevention of poaching in the studies included in this review mean the results of this review cannot be considered generalisable to other criminal acts involving terrestrial species, or environments outside of Africa and Asia (the locations of the included articles), and highlights the need for further research in this area.

As the protection of the environment and the species within it becomes more mainstream, governments and businesses are investing large sums to support the prevention of crimes against species. The investment of large sums into research and prevention requires stakeholders to accurately invest in what has been proven to be effective. This review provides a starting point for decision makers, but based on the very limited research available, it is impossible to be certain if these two types of intervention are the most effective in terms of preventing crime against the target species.

This review provides researchers in a variety of fields with a basis on which to plan future research to evaluate the effectiveness of prevention techniques for the 
protection of species, and justify the use of funds to fill the large gap in the existing literature with more targeted outcome evaluations of existing and novel SCP techniques.

In the process of conducting this review, several limitations were identified relating to the studies included in this survey, as well as the limitations of studies relating to this topic in general. These will now be discussed with a view to informing future primary evaluations.

\section{Limitations of studies}

Accuracy of data-an ever-present issue with species crime relates to the 'dark figure' of illegal activities, that is, a large proportion of crimes are likely to go undiscovered (Biderman and Reiss 1967; Lemieux 2014). This presents a significant problem for primary studies of intervention, and subsequent systematic reviews. It makes the collection of accurate primary data a complex but important task for future research to better assess and understand the impact of illegal activities involving species.

Age of existing studies-across studies, the methods employed, and the accuracy of the data varied significantly. The studies included in this review were published between 1990 and 2016, with the data originating from the 1970s onwards. The age of the data and the age of some of the studies means the results cannot be considered an up to date representation of the effect of patrolling for the current prevention of crime against species. More up to date outcome evaluations are needed to establish the effectiveness of prevention techniques internationally.

Changes in practices-as increasing funding and technology has been channelled to anti-poaching patrols since the 1970s, the systematic nature of record keeping has steadily improved. Researchers must take this into account when comparing data from one period, where rangers were using paper maps and notebooks, to another, where GPS equipment, drones and other technology were used. Any observed differences concerning, for example, the detection rates between such periods may reflect better detection, or more accurate data-recording. In addition, differences between areas may be due to variable access to such technology, which is unlikely to be ubiquitous across places.

Variation in terminology - the terminology used in different fields of research has led to a situation where some keywords have become used generically to describe a multitude of scenarios from disparate fields of research. Several conservation studies discussed activities such as 'poaching' and 'by-catch' as being one of many elements impacting the local ecology. However, the focus of their research, whilst aiming to benefit the local ecology in general, did not focus specifically on preventing wildlife crimes. Studies relating to conservation may have dealt with issues that were detrimental to the environment but were not technically illegal. As the focus of this review was to establish what interventions exist to prevent terrestrial wildlife crime and how effective these methods are, the conservation studies initially identified did not ultimately meet the inclusion criteria.

Variation in legal/illegal activities-actions that impact upon species may be deemed illegal in one country but not in another. Due to differences in law between countries, the authors of this review selected articles where prevention methods were being used to tackle illicit activities against species. Kurland et al (2017) incorporated both conservation and crime prevention methods, in a literature review. This systematic review could be supplemented with information from other systematic reviews of methods of prevention/intervention techniques focused solely on wildlife conservation. By encouraging the production and updating of reviews focused on TS crime, researchers and decision makers will have a larger quantitative and qualitative data set on the effectiveness of methods for protecting terrestrial species.

Diversity of prevention methods-in their analysis of a decade of projects funded by The Tiger Funds, Gratwicke et al. (2007) argued that the variety of intervention types and methodologies used were too diverse for them to effectively conduct a meta-analysis. The same can be said here. The validity of future work depends on standardising as far as possible the data (e.g. including recording practices) and analytic approaches taken in primary studies to make it possible for future systematic reviews to include a quantitative and qualitative synthesis.

Funding-Limited funding for projects relating to wildlife crime is a continuing issue internationally. Investments have been made in recent years to tackle the problem of international wildlife crime, but continued financial support is not guaranteed. Moreover, the majority of the research undertaken to date has concerned conservation. Whilst conservation studies are a useful source of information relating to the topic of interest, conservation studies tend to indirectly examine the impact of interventions on crime associated with the international wildlife trade. Clearly, future work that seeks to also examine the latter will be necessary if we are to learn what works to reduce this form of offending.

The expediency of solutions is one of the major issues with transposing ideas for tackling crime. Whilst technological solutions may theoretically provide some deterrence and detection benefits, it is only when there is sufficient funding for training, deployment, operation and maintenance, that such prevention methods are truly feasible. And, without evidence to show that particular 
approaches work, limited resources may be squandered on good ideas that fail to reduce crime or costs effectively.

Publication Bias-publication bias is a complex issue in relation to conservation research internationally. The most prominent countries in relation to biodiversity and conservation, are also those with developing economies. A study carried out by Fazey et al. (2005) examined the main barriers that prevent conservation research conducted in developing countries from reaching international audiences. These included language barriers, as well as access to technology and funding to be used to conduct and publish the results of the research. Unless these issues are addressed valuable research and potential solutions to crimes involving TS may continue to be overlooked.

The conservation and crime science fields should actively seek to support the retroactive publication of research that has to this date not been published due to the issues described above, and provide a platform by which research and researchers from around the world can present their findings. As books, journals and subsequently research databases incorporate a wider variety of text from international sources, there is likely to be more relevant data and literature available, therefore, the authors hope that future systematic reviews will incorporate literature that has at this time been omitted due to the publication bias described above.

Displacement of illegal activity-the displacement of illegal activity was not discussed directly in any of the studies reviewed but alluded to as an important avenue for future research. Identifying the impact of interventions in areas beyond the focus of the intervention would indicate whether poaching activity is being actively reduced by patrolling or is being spatially displaced to nearby locations (Linkie et al. 2015). In addition to spatial displacement, target displacement where criminals may choose to target other species should also be considered in future research. In the case of urban crime, it has been shown that police patrols do not appear to displace crime (see Bowers et al. 2011), but context matters and this may not be the case for poaching (Johnson et al. 2014).

Interrater-reliability-The identification of eligible articles and the extraction of information was performed by the main author, without additional checks completed by the other authors to establish if the original filtering and data extraction were performed accurately. The Systematic Review would have benefited from other individuals performing data identification and extraction to assess interrater reliability (Belur et al. 2018).

Future research into the effectiveness of Situational Crime Prevention techniques for preventing crimes against species, should not only look at assessing the effectiveness of novel technological solutions, but also review methods already being used that are assumed to be effective, but for which there exists no supporting evidence. Once more outcome evaluations as to the effectiveness of SCP methods exist in the literature relating to species crime, a more comprehensive systematic review can be carried out to update stakeholders on the existing literature and evidence to support decision making.

\section{Conclusion}

The articles identified in this review provide an insight into the difficulties faced by various stakeholders in identifying the most applicable methods for preventing crime against species. It should be clear from the small number of articles that were included in this review that there is very little research on what works to prevent species crime. This issue could be addressed in two ways: Firstly, through retrospective publication of assessment research not readily available. Secondly, through conducting new research designed to assess the effectiveness of existing and proposed prevention measures. The impact of crimes against species, such as dwindling numbers and impending extinctions that were described in the included research (written over three decades ago) remains a significant issue that needs to be addressed. Many organisations are devoted to preventing the extinction of iconic species internationally, often involving significant financial investment, but research informing or evaluating their impact is lacking. Without more empirical evidence to present to such conservation organisations about the effectiveness of prevention methods, it will be a continuing challenge to justify the need for funding and supporting prevention efforts, such as community outreach and patrolling. With increasing financial pressure, the limited evidence to support current prevention techniques and developing new methods, the challenge to prevent the extinction of species is likely to continue.

\section{Acknowledgements \\ The authors would like to thank the anonymous reviewers for their helpful comments.}

\section{Authors' contributions}

All authors read and approved the final manuscript.

\section{Funding}

Thank you to the EPSRC for providing funding to support the PhD research that provide the basis for this article. No other outside funding was used to support this work.

\section{Availability of data and materials \\ Not applicable.}

Ethics approval and consent to participate

Not applicable.

Consent for publication

Not applicable.

Competing interests

The authors declare that they have no competing interests. 
Received: 29 June 2020 Accepted: 17 December 2020

Published online: 06 January 2021

\section{References}

Belur, J., Tompson, L., Thornton, A., \& Simon, M. (2018). Interrater reliability in systematic review methodology: exploring variation in coder decisionmaking. Sociological Methods \& Research. https://doi.org/10.1177/00491 24118799372.

Biderman, A. D., \& Reiss, A. J., Jr. (1967). On exploring the" dark figure" of crime. The Annals of the American Academy of Political and Social Science, 374(1), $1-15$.

Blattner, C. E. (2019). The recognition of animal sentience by the law. Journal of Animal Ethics, 9(2), 121-136.

Borrion, H., Amiri, A., Delpech, D., \& Lemieux, A. M. (2019). Experimental assessment of the viability of using ground penetrating radar for metal wire-snare detection. Crime Science, 8(1), 1-10.

Bowers, K. J., Johnson, S. D., Guerette, R. T., Summers, L., \& Poynton, S. (2011). Spatial displacement and diffusion of benefits among geographically focused policing initiatives: a meta-analytical review. Journal of Experimental Criminology, 7(4), 347-374.

Cooney, R., Roe, D., Dublin, H., Phelps, J., Wilkie, D., Keane, A., \& Biggs, D. (2017). From poachers to protectors: engaging local communities in solutions to illegal wildlife trade. Conservation Letters, 10(3), 367-374.

Cornish, D. B. (1994). The procedural analysis of offending and its relevance for situational prevention. Crime prevention studies, 3, 151-196.

Cornish, D. B., \& Clarke, R. V. (2003). Opportunities, precipitators and criminal decisions: a reply to Wortley's critique of situational crime prevention. Crime Prevention Studies, 16, 41-96.

Daerr, E. G. (2001). Parks attract ginseng poachers. National Parks (p. 12). Ann Arbor: ProQuest Central.

Donnermeyer, J. F., \& Barclay, E. (2005). The policing of farm crime 1. Police Practice and Research, 6(1), 3-17.

Driscoll, C. A., Macdonald, D. W., \& O'Brien, S. J. (2009). From wild animals to domestic pets, an evolutionary view of domestication. Proceedings of the National Academy of Sciences, 106 (Supplement 1), 9971-9978.

Fazey, I., Fischer, J., \& Lindenmayer, D. B. (2005). Who does all the research in conservation biology? Biodiversity \& Conservation, 14(4), 917-934.

Gratwicke, B., Seidensticker, J., Shrestha, M., Vermilye, K., \& Birnbaum, M. (2007). Evaluating the performance of a decade of Save The Tiger Fund's investments to save the world's last wild tigers. Environmental Conservation, 34(03), 255-265.

Hilborn, R., Arcese, P., Borner, M., Hando, J., Hopcraft, G., Loibooki, M., \& Sinclair, A. R. (2006). Effective enforcement in a conservation area. Science, 314(5803), 1266-1266

Jachmann, H., \& Billiouw, M. (1997). Elephant poaching and law enforcement in the central Luangwa Valley, Zambia. Journal of Applied Ecology, 34, 233-244.

Johnson, S. D., Guerette, R. T., \& Bowers, K. (2014). Crime displacement: what we know, what we don't know, and what it means for crime reduction. Journal of Experimental Criminology, 10(4), 549-571.

Johnson, S. D., Tilley, N., \& Bowers, K. J. (2015). Introducing EMMIE: an evidence rating scale to encourage mixed-method crime prevention synthesis reviews. Journal of Experimental Criminology, 11(3), 459-473.

Kurland, J., Pires, S. F., McFann, S. C., \& Moreto, W. D. (2017). Wildlife crime: a conceptual integration, literature review, and methodological critique. Crime Science, 6(1), 4.

Larkcom, E., \& Delpech, R. (2013). Biology for Edexcel Internation GCSE. London: Hodder Education.

Leader-Williams, N., Albon, S. D., \& Berry, P. S. M. (1990). Illegal exploitation of black rhinoceros and elephant populations: patterns of decline, law enforcement and patrol effort in Luangwa Valley, Zambia. Journal of Applied Ecology, 27, 1055-1087.

Lemieux, A. M. (Ed.). (2014). Situational prevention of poaching. London: Routledge.

Lemieux, A. M. (Ed.). (2020). The Poaching Diaries (vol. 1): Crime Scripting for Wilderness Problems (pp. 108-109). Phoenix, AZ: Center for Problem Oriented Policing, Arizona State University.
Linkie, M., Martyr, D. J., Harihar, A., Risdianto, D., Nugraha, R. T., Leader Nugrahaugraha, Nu., \&Wong, W. M. (2015). EDITOR'S CHOICE: safeguarding Sumatran tigers: evaluating effectiveness of law enforcement patrols and local informant networks. Journal of Applied Ecology, 52(4), 851-860.

Lynch, M. J., Barrett, K. L., Stretesky, P. B., \& Long, M. A. (2017). The neglect of quantitative research in green criminology and its consequences. Critical Criminology, 25, 1-16.

Martin, E., Martin, C., \& Vigne, L. (2013). Successful reduction in rhino poaching in Nepal. Pachyderm, 54, 66-73.

Maruna, S., \& Copes, H. (2005). What have we learned from five decades of neutralization research? Crime and Justice, 221-320.

Miranda Montero, J. J., Wright, E. M., \& Khan, M. N. (2019). Illegal logging, fishing, and wildlife trade: the costs and how to combat it (pp. 1-70). Washington, DC: The World Bank.

Mlinarić, A., Horvat, M., \& Šupak Smolčić, V. (2017). Dealing with the positive publication bias: why you should really publish your negative results. Biochemia medica: Biochemia medica, 27(3), 1-6.

Moreto, W. D., Lemieux, A. M., Rwetsiba, A., Guma, N., Driciru, M., \& Kirya, H. K. (2014). Law enforcement monitoring in Uganda. In A. M. Lemieux (Ed.), Situational Prevention of Poaching (pp. 82-101). London: Routledge.

NFU Mutual. (2019). Rural Crime Report 2019. https://www.nfumutual.co.uk/ farming/ruralcrime/

Nellemann, C., Henriksen, R., Raxter, P., Ash, N., \& Mrema, E. (2014). The environmental crime crisis: threats to sustainable development from illegal exploitation and trade in wildlife and forest resources. A UNEP Rapid Response Assessment. Nairobi: United Nations Environment Programme.

Nurse, A. (2016). Beyond the property debate: animal welfare as a public good. Contemporary Justice Review, 19(2), 174-187.

PANIU. (2015a). Plant \& Agricultural National Intelligence Unit-Metropolitan Police PANIU 24th Report. http://content.met.police.uk/Article/Quarterlyreports/1400030610576/1400030610576

PANIU. (2015b). Plant \& Agricultural National Intelligence Unit—Metropolitan Police PANIU 7 Year Report. http://content.met.police.uk/Article/Quart erly-reports/1400030610576/1400030610576

Petticrew, M. (2001). Systematic reviews from astronomy to zoology: myths and misconceptions. British Medical Journal, 322(7278), 98.

Pires, S. F., \& Moreto, W. D. (2011). Preventing wild life crimes: solutions that can overcome the 'Tragedy of the Commons.'European Journal on Criminal Policy and Research, 17(2), 101-123.

Sidebottom, A. (2013). On the application of CRAVED to livestock theft in Malawi. International Journal of Comparative and Applied Criminal Justice, 37(3), 195-212.

Sollund, R. (2016). The animal other: legal and illegal theriocide. In Greening criminology in the 21st century (pp. 93-113). London: Routledge.

Steinmetz, R., Srirattanaporn, S., \& Mor-Tip, \& Seuaturien, N. . (2014). Can community outreach alleviate poaching pressure and recover wildlife in South-East Asian protected areas? Journal of Applied Ecology, 51(6), 1469-1478.

Swanson, C. R. (1981). Rural and agricultural crime. Journal of Criminal Justice, 9(1), 19-27.

Sykes, G. M., \& Matza, D. (1957). Techniques of neutralization: a theory of delinquency. American sociological review, 22(6), 664-670.

UN News. (2016). UN-backed fund expands wildlife protection plan to 19 countries in Africa and Asia. http://www.un.org/apps/news/story asp?NewsID=54193\#.WOT6WLGZOt8

UNODC. (2017). Global Programme for Combatting Wild life and Forest Crime. https://www.unodc.org/unodc/en/wildlife-and-forest-crime/globa I-programme.html

White, R. (2013). Crimes against nature: environmental criminology and ecological justice. Cullompton: Willan.

What Works. (2015). Neighbourhood Watch. http://whatworks.college.polic e.uk/toolkit/Pages/Intervention.aspx?!nterventionlD $=8$

WWF. (2017). Wildlife crime initiative. http://wwf.panda.org/what_we_do/ how_we_work/our_global_goals/species_programme/wildlife_trade/ wildlife_crime_initiative/

\section{Publisher's Note}

Springer Nature remains neutral with regard to jurisdictional claims in published maps and institutional affiliations. 